\title{
Finite Element Analysis on Rigidity and Strength of a Vehicle Type Clutch Pedal
}

\author{
Yuan Han \\ College of Automobile Engineering, Wuxi Institute of Commerce, Wuxi, Jiangsu ,China, 214153 \\ email:156204841@qq.com
}

Key words: Clutch pedal, Rigidity, Strength, Finite element analysis

\begin{abstract}
By using a finite element analysis method in this paper, the rigidity and strength of a vehicle type clutch pedal was simulated and analyzed, in order to verify whether the rigidity and strength of the clutch pedal meet the design requirements, and thus to provide theoretical basis for the freezing of the vehicle data.
\end{abstract}

\section{Introduction}

Clutch pedal is a manipulator for manual automobile clutch assembly, an important part of the human-computer interaction mechanism for driver and vehicles, and one of the mechanisms that is used very frequently by driver; its performance directly determines the user's safety and operability [1-3]. The clutch pedal as one of the important auto parts must have enough rigidity and strength, to ensure the driving safety of vehicles [4-6]. In order to ensure that a vehicle type clutch pedal has enough rigidity and strength, the rigidity and strength of the vehicle type clutch pedal were analyzed and calculated in this paper by using the finite element analysis method, the position of concentrated stress on the vehicle type clutch pedal was found out, and the related evaluation on the results was carried out to provide strong theoretical basis for the follow-up design.

\section{Establishment of a Finite Element Model of Clutch Pedal}

Based on the 3D mathematical model of a vehicle type clutch pedal, a finite element analysis model of the vehicle type clutch pedal was established, as shown in Figure 1. Sheet metal parts were dispersed by SHELL unit, the clutch pedal body was simulated by use of SOLID unit, and weld joints were simulated by RBE2 unit, and the connecting bolts between the clutch pedal body and clutch pedal rack were simulated by use of CBAR unit. There are a total of 8271 nodes and 5563 units in the completed finite element analysis model of the clutch pedal.

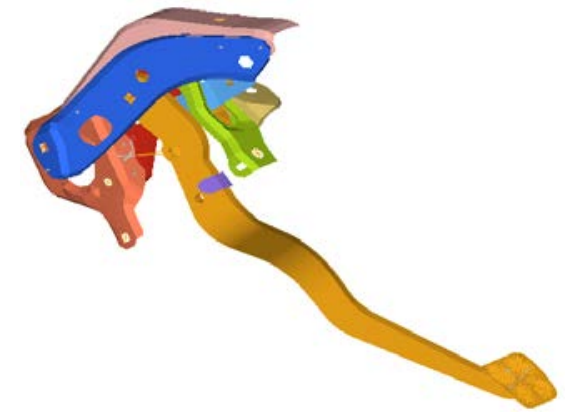

Figure 1 Finite element model for analysis on rigidity and strength of a vehicle type clutch pedal

\section{Finite Element Analysis on Rigidity of Clutch Pedal}

Boundary Conditions for Finite Element Analysis on Rigidity of Clutch Pedal. All degrees of freedom of 123456 on the joints of the clutch pedal and the body were constrained, the degrees of freedom of 13456 at the clutch pedal push rod were constrained, but a rotational degree of freedom was only kept, and the output end of the clutch pedal was fixed in the middle position of the working travel of the pedal; then a load was applied according to the requirements of QC/T 
788-2007 Performance requirements and bench test methods of automobile pedal device, and the applied load was positioned on the geometric center of the pedal. The details are shown in Table 1 and Figure 2.

Table 1 Load conditions for rigidity analysis

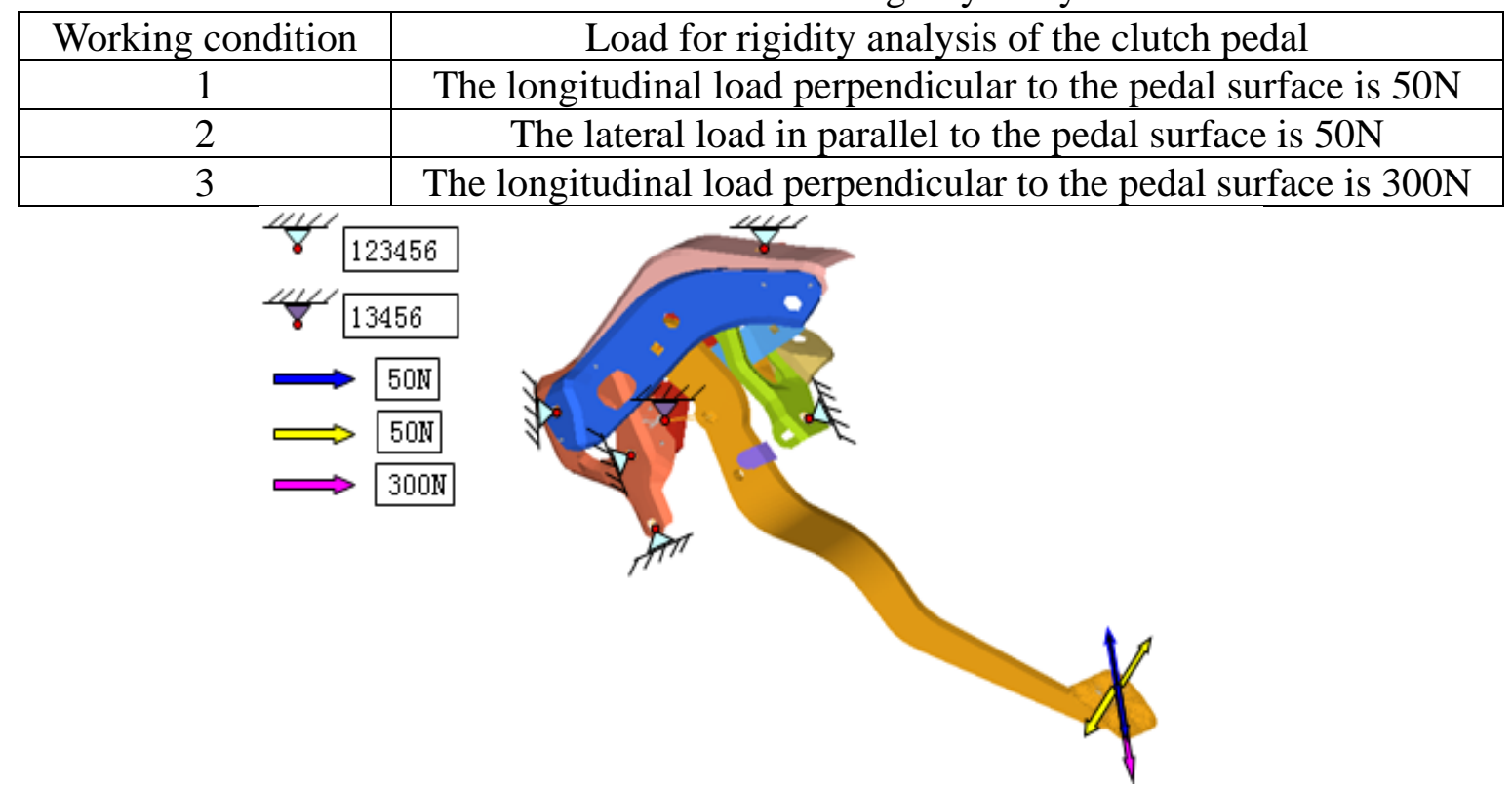

Figure 2 Boundary conditions for rigidity analysis of clutch pedal

Simulation Analysis Results of Rigidity of the Clutch Pedal. Displacement nephograms of the clutch pedal under working conditions are shown in Figures 3, 4 and 5 through simulated analysis.

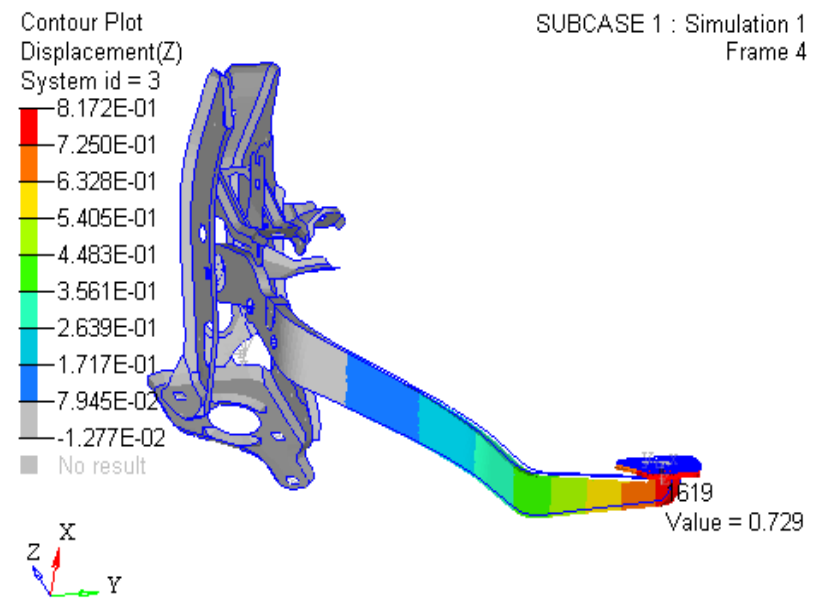

Figure 3 Displacement nephogram of the clutch pedal under working condition 1

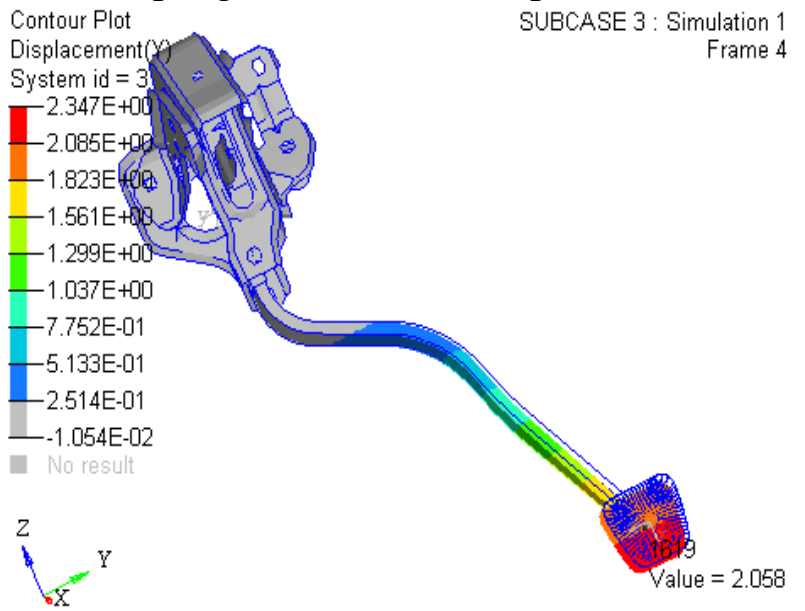

Figure 4 Displacement nephogram of the clutch pedal under working condition 2 


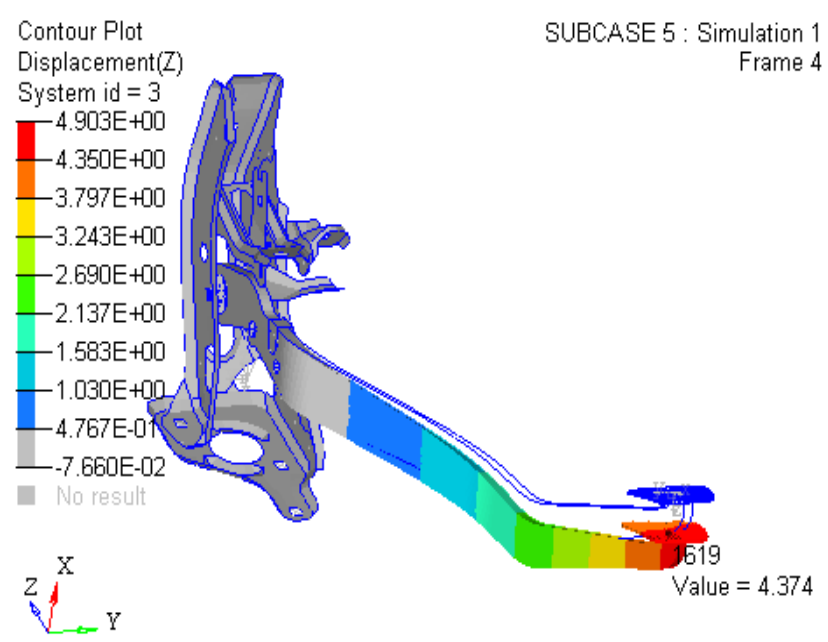

Figure 5 Displacement nephogram of the clutch pedal under working condition 3

The statistics on rigidity analysis results of the clutch pedal are shown in Table 2. It can be seen from the table 2 that under the action of $50 \mathrm{~N}$ longitudinal force, the longitudinal displacement of the vehicle type clutch pedal is $0.729 \mathrm{~mm}$, which meets the regulatory requirements (under the action of $50 \mathrm{~N}$ longitudinal force, the longitudinal displacement is less than $2 \mathrm{~mm}$ ); under the action of $50 \mathrm{~N}$ lateral force, the lateral displacement of the vehicle type clutch pedal is $2 \mathrm{~mm}$, which meets the regulatory requirements (under the action of $50 \mathrm{~N}$ lateral force, the lateral displacement is less than $5 \mathrm{~mm}$ ); under the action of $300 \mathrm{~N}$ longitudinal force, the longitudinal displacement of the vehicle type clutch pedal is $4.374 \mathrm{~mm}$, which meets the regulatory requirements (under the action of $300 \mathrm{~N}$ longitudinal force, the lateral displacement is less than $5 \mathrm{~mm}$ ).

Table 2 Rigidity analysis results of the clutch pedal

\begin{tabular}{|c|c|c|c|c|}
\hline $\begin{array}{c}\text { Working } \\
\text { condition }\end{array}$ & $\begin{array}{c}\text { Displacement } \\
\text { direction }\end{array}$ & $\begin{array}{c}\text { Load size } \\
(\mathrm{N})\end{array}$ & $\begin{array}{c}\text { Displacement of } \\
\text { loading point }(\mathrm{mm})\end{array}$ & $\begin{array}{c}\text { Rigidity value } \\
(\mathrm{N} / \mathrm{mm})\end{array}$ \\
\hline 1 & $\Delta \mathrm{LP}$ & 50 & 0.729 & 68.59 \\
\hline 2 & $\Delta \mathrm{LT}$ & 50 & 2.058 & 24.30 \\
\hline 3 & $\Delta \mathrm{LP}$ & 300 & 4.374 & 68.59 \\
\hline
\end{tabular}

\section{Finite Element Analysis on Strength of Clutch Pedal}

Boundary Conditions For Finite Element Analysis on Strength of Clutch Pedal. All degrees of freedom of 123456 on the joints of the clutch pedal and the body were constrained, the degrees of freedom of 13456 at the clutch pedal push rod were constrained, but a rotational degree of freedom was only kept, and the output end of the clutch pedal was fixed in the middle position of the working travel of the pedal; then a load was applied according to the requirements of QC/T 788-2007 Performance requirements and bench test methods of automobile pedal device, as shown in Figure 6, perpendicular to the clutch pedal surface. The longitudinal force $\mathrm{P}$ was applied onto the geometric center of the clutch pedal before unloading. $800 \mathrm{~N}$ force is applied onto the clutch pedal.
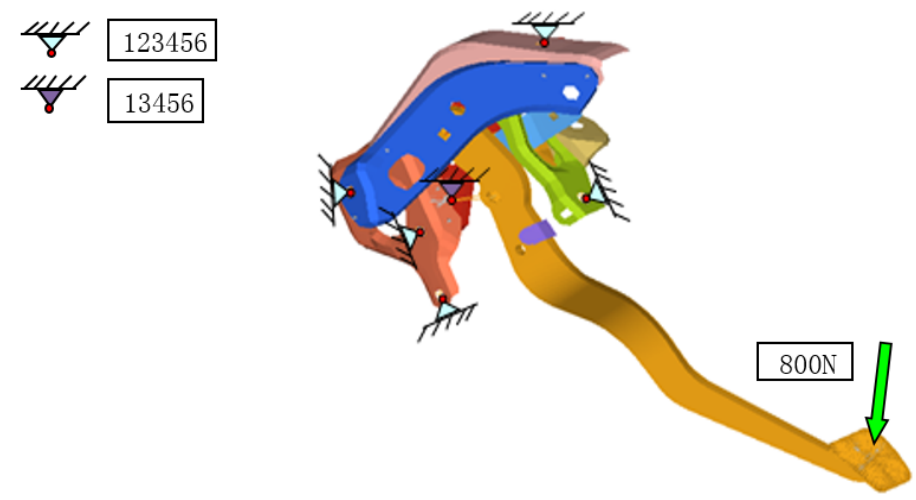

Figure 6 Boundary conditions for strength analysis of clutch pedal 
Finite Element Analysis Results of Strength of Clutch Pedal. The nephograms of the vehicle type clutch pedal are shown in Figures 7, 8, 9 and 10 through simulated analysis.

It can be seen from Figure 7 that the maximum stress point of the clutch pedal is in the middle part of the pedal arm, the maximum stress value is $232.035 \mathrm{MPa}$, and the amount of plastic corresponding to the maximum stress is available from Figure 7; that is, the value is $15.3 \%$, the clutch pedal is overall made of Q345 material, the yield strength is $324 \mathrm{MPa}$, and the percentage of elongation is $22 \%$, which meet the using requirements.

It can get from Figure 9 and Figure 10 that the displacement is $160.551 \mathrm{~mm}$ when the vehicle type clutch pedal is already loaded, the displacement is $157.186 \mathrm{~mm}$ when unloading is completed, and the maximum residual deformation is $3.365 \mathrm{~mm}$; according to the requirements of $\mathrm{QC} / \mathrm{T}$ 788-2007 Performance requirements and bench test methods of automobile pedal device, if there is an $800 \mathrm{~N}$ load on the clutch pedal, the maximum residual deformation of the pedal is less than $5 \mathrm{~mm}$, so the model pedal meets the design requirements.

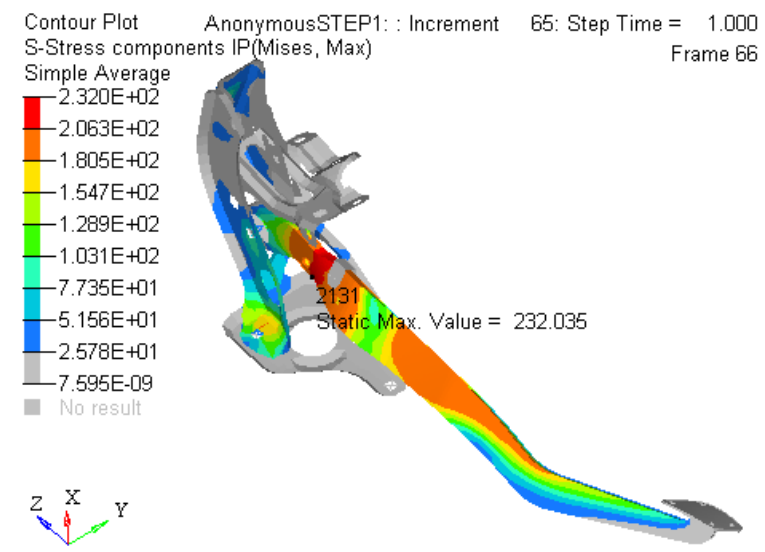

Figure 7 Stress nephogram of the clutch pedal loaded

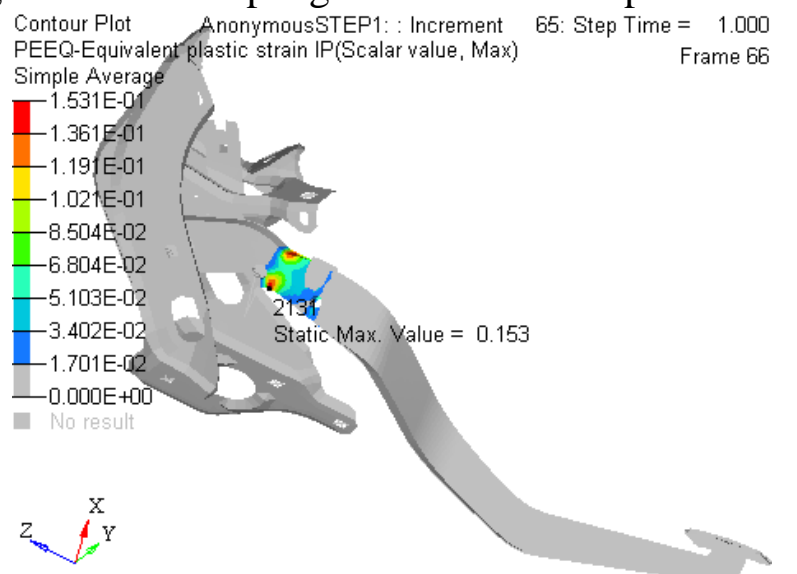

Figure 8 Plastic strain nephogram of the clutch pedal loaded

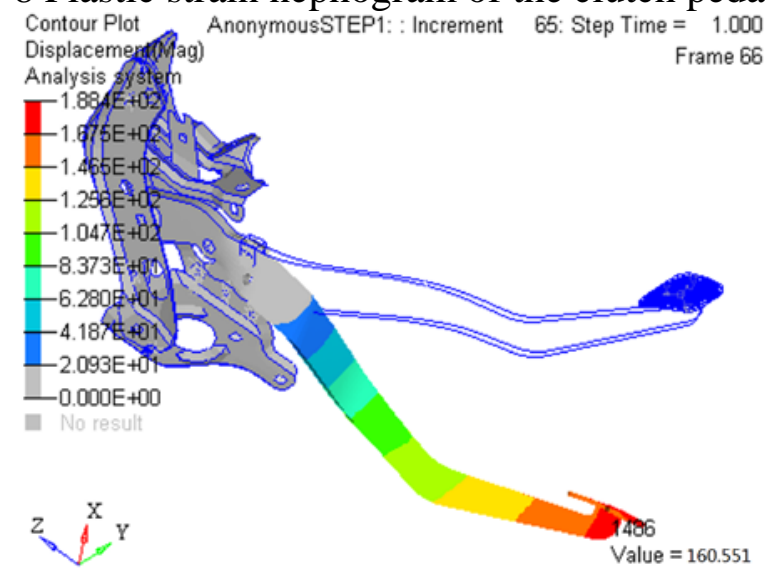

Figure 9 Displacement nephogram of the clutch pedal loaded 


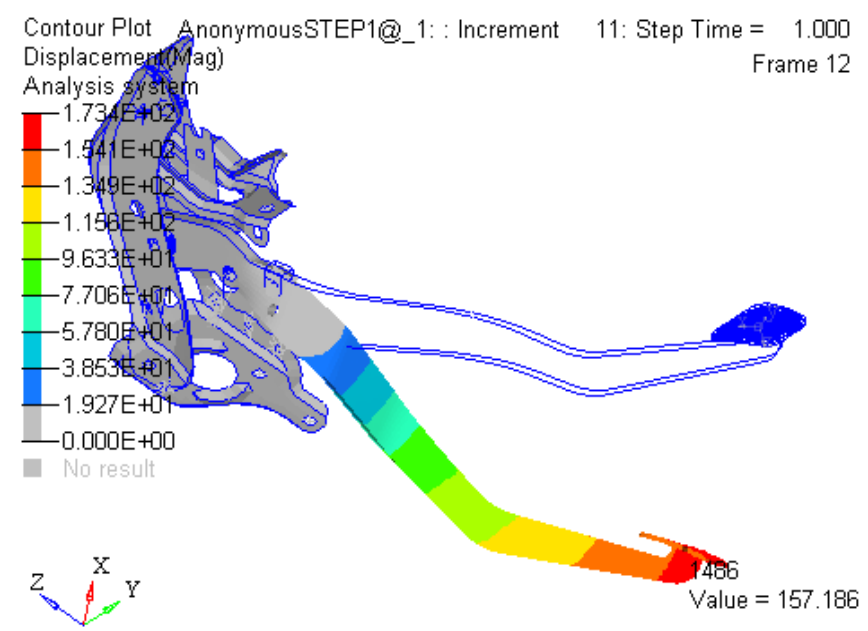

Figure 10 Displacement nephogram of the clutch pedal unloaded

\section{Conclusion}

In this paper, a vehicle type clutch pedal was analyzed and studied using the finite element analysis method, and the research results show that the longitudinal rigidity of the clutch pedal is $68.59 \mathrm{~N} / \mathrm{mm}$, the lateral rigidity is $24.3 \mathrm{~N} / \mathrm{mm}$, the maximum stress value of the clutch pedal is 232.035MPa, less than the yield limit of Q345 material (324MPa), and the maximum residual deformation is $3.365 \mathrm{~mm}$, which is less than $5 \mathrm{~mm}$ as required in QC/T 788-2007 Performance requirements and bench test methods of automobile pedal device.

\section{References}

[1] Ma Cheng, Wang Jiang, et al. Optimized design of pedal force of clutch pedal [J]. Journal of Agricultural Equipment \& Vehicle Engineering, 2015 (4): 71-73

[2] Yan Yifei, Zhang Hao, et al. Checking and review of clutch pedal force and stroke of a mini truck [J] Journal of Shanxi Auto, 2017 (5), 40-46

[3] Song Yangyong, Zhang Ruiqian et al. Finite element analysis and optimization of automobile clutch pedal component [J]. Journal of Mechanical engineering and manufacturing and automation, 2016 (6): 18 to 20

[4] Mou Xuelei, Li Cuiping, et al. Finite element analysis on strength of automobile side pedal [J] Journal of Auto parts, 2015 (7): 47-50

[5] Liu Shaohua, Fang Ya, et al. Analysis and research on finite element strength of automobile rear protective device [J] Journal of Chongqing Jiaotong University: Natural science edition, 2015 (2): 137-140

[6] Sun Xuemin, Wei Qingtan, et al. Nonlinear Finite Element Analysis of Automobile Leaf Spring Based on ANSYS [J]. Agricultural Equipment and Vehicle Engineering, 2017(3):43-46 